Journal of Biotechnology and Strategic Health Research

Derleme / Review

http://dergipark.org.tr/tr/pub/bshr

\title{
COVID-19 Pandemi Sürecinde Şehir Sağlı̆̆ı Çalışmaları
}

\author{
Urban Health Studies in COVID-19 Pandemic Process
}

(iD) $\triangle$ Pınar Özdemir Deniz, (D) Emine Didem Evci Kiraz

Aydın Adnan Menderes University, Medical Faculty, Department of Public Health, Aydın

ORCID ID: Pınar Özdemir Deniz 0000-0001-8813-6970, Emine Didem Evci Kiraz 0000-0003-0090-5590

*Sorumlu Yazar / Corresponding Author: Arş. Gör. Pınar Özdemir Deniz , e-posta / e-mail: pinar.ozdemir@adu.edu.tr

Geliş Tarihi / Received : 24-04-2020 Kabul Tarihi / Accepted: 25-04-2020 Yayın Tarihi / Online Published: 30-04-2020

Atıf Gösterimi/How to Cite: Deniz Ö.P., Evci Kiraz E.D. COVID-19 Pandemi Sürecinde Şehir Sağlığı Çalışmaları, J Biotechnol and Strategic Health Res. 2020;1(Özel Sayı):147-151

Öz

COVID-19, damlacık yoluyla insandan insana çok hızlı bulaşmaktadır. Bulaşı önlemek için toplu yaşam alanı olan şehirlerde mecburi değișiklikler, yenilikler yapılmak zorunda kalındığı görülmektedir. COVID-19 salgını sonucu olușacak farkındalık ve tecrübeler, daha iyi ve daha sürdürülebilir toplumlar ve şehirler inşa etmek için bir firsata dönüştürülmelidir. Bu çalışmada pandemi sürecinde şehir sağlığı ile ilgili gelişen yeni yaklaşımlara yer verilmiştir.

Anahtar COVID-19, şehir sağlığı, pandemi, şehir, sağllk hizmetleri

Kelimeler

Abstract

COVID-19 is transmitted very quickly from person to person through droplets. In order to prevent contamination, it is seen that there is a compulsory change and innovations in cities with collective living areas. The awareness and experiences that will result from the COVID-19 outbreak should be turned into an opportunity to build better and more sustainable communities and cities. In this study, new approaches about urban health are discussed in the pandemic process.

Keywords COVID-19, urban health, pandemic, city, health services 


\section{GIIRIŞ}

Çin’in Hubei Eyaleti, Vuhan Şehrinde, 31 Aralık 2019'da pnömoni kümelenmesi dikkat çekmiş, 7 Ocak 2020'de ise bu duruma neden olan etkenin insanlarda tespit edilmemiş yeni bir koronavirüs olduğu belirtilmiş, COVID-19 olarak adlandırılmıştır. Türkiye'de ilk COVID-19 vakası 11 Mart 2020 de açıklanmıştır. ${ }^{1}$ Dünya Sağlık Örgütü (DSÖ) aynı tarihte bu salgını pandemi olarak tüm Dünyàya duyurmuştur. ${ }^{2}$

Koronavirüs (COVID-19), damlacık yoluyla insandan insana çok hızlı bulaşmaktadır. Ayrıca hasta bireylerin öksürme, hapşırma dolayısıyla ortaya saçtığı sekresyonlara diğer kişilerin elleri ile temas etmesi sonrasında ellerini ağız, burun veya göz mukozasına götürmesi ile de bulaş olmaktadır. COVID-19'un bulaştırıcılık süresi semptomatik dönemden 1-2 gün önce başlayıp semptomların kaybolmasıyla sona erdiği düşünülmektedir. ${ }^{1}$

$\mathrm{Bu}$ nedenle bulaştırıcılığın önlenmesinde sosyal izolasyon, kişisel koruyucu ekipman kullanımı (maske, eldiven vb.) ve sosyal mesafeyi koruma (en az 1 metre) gibi insanların birbiri ile temasını kesecek yöntemler oldukça önem kazanmıştır. ${ }^{3}$ Toplu yaşam alanlarında insan hareketlerinin yeniden düzenlenmesi için alınan önlemler incelendiğinde, şehirlerde mecburi değişiklikler, yenilikler yapılmak zorunda kalındığ 1 görülmektedir. Çünkü şehirlerde artmış nüfus yoğunluğu, insanlar arasında yakın temas, yüksek hareketlilik ve toplu taşıma araçları, ortak kullanım alanları enfeksiyonun hızla yayılmasına neden olan unsurlardır. ${ }^{4}$ İlk vakaların görüldüğü Çin'de yapılan çalışmalarda, okulların kapatılması, insanların evlerinde kalmalarına zorlanması, toplu yaşam alanları kullanımı kısıtlanmasının COVID-19 vaka sayısında en etkili yaklaşım olduğu belirtilmektedir., ${ }^{5,6}$

COVID-19 ile mücadelede T.C. İçişleri Bakanlığı tarafından şehirlerde düzenlemeler yapılmasına yönelik "Bazı bireylere sokağa çıkma yasağı getirilmesi, umuma açık istirahat ve eğlence yerleri, SPA ve spor salonlarının halkın erişimine kapatılması, lokantalarda oturmaya müsaade etmeden sadece paket servis yapılması, marketlerin çalışma saati ve market- lerde alışveriş yapan müşteri sayısı düzenlemeleri vb.” alınan kararlar Tablo 1'de sunulmuştur. ${ }^{7}$

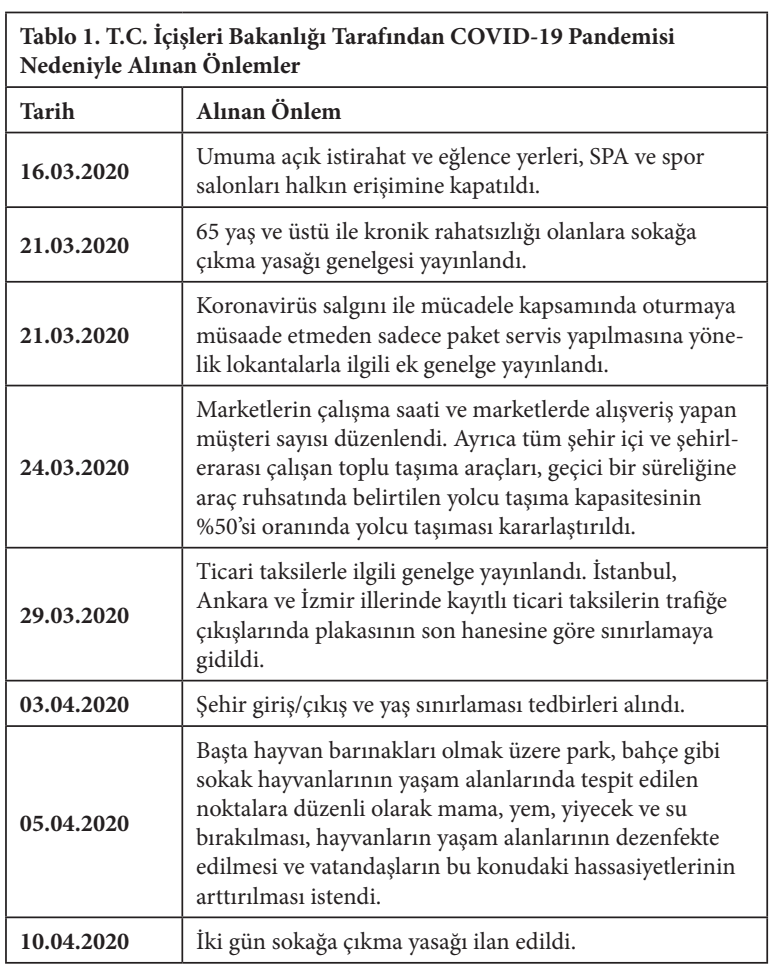

İzolasyon bulaşı önlemede oldukça etkili olması yanısıra, insanlar üzerindeki negatif etkileri göz ardı edilmemelidir. İzolasyon uygulandığı her yerde tüm nüfusun günlük yaşamını aynı anda bozmuştur. ${ }^{8}$ Yapılan bazı çalışmalarda bu durumun posttravmatik stres bozukluğu, anksiyete ve öfke nöbetlerini tetikleyebileceğine değinilmiştir. ${ }^{9}$ Ayrıca izolasyon ile gelen sedanter yaşam, kardiyovasküler hastalıklar gibi kronik hastalıkları tetikleyebilir. Bu dönem edinilen tecrübeler ile şehirlerde bireysel fiziksel aktiviteyi arttırmaya yönelik dış ortam uygulamaları (örneğin toplu taşıma kullanma yerine yürüyüş ve bisiklete binmeyi teşvik edecek girişimler) ve ev içi uygulamaları (örneğin kapalı ortam, yaşa uygun egzersiz programları, oyunlar, hobi programları, yaşa uygun dijital platformların tanıtım ve eğitimleri) salgın sonrası için avantaja dönüştürülebilir. $^{10}$ 


\section{Şehirlerde Pandemi Riskleri ve Yeni Yaklaşımlar,} Türkiye ve Dünya Örnekleri

Korunma önlemlerinin hastalığın tedavisi kadar ve belki daha fazla önemli olduğu COVID-19 pandemi sürecinde şehir sağlığı ile ilgili çalışmalar geri planda kalmıştır. DSÖ, CDC, EC, EU gibi uluslararası sağlık kuruluşlarının ve T.C. Sağlık Bakanlığı’nın web adreslerinde pandemi sürecinde şehir sağlığı konusuna yer verilmemiştir. Akademik veri tabanlarında "Urban Health, COVID-19" anahtar kelimeleri birlikte taratıldığında listelenen yayın sayısı oldukça azdır. Konu ile ilgili bazı dikkat çekici yayınlar Tablo 2'de listelenmiştir.

\begin{tabular}{|c|c|c|}
\hline Yayın adı & Tarihi & Önemli noktalar \\
\hline $\begin{array}{l}\text { "Urban nature as a } \\
\text { source of resilience } \\
\text { during social } \\
\text { distancing amidst } \\
\text { the coronavirus } \\
\text { pandemic"11 }\end{array}$ & Nisan, 2020 & $\begin{array}{l}\text { Sosyal izolasyon uygulanırken, şehirlerde } \\
\text { kişilerin doğa ile temasının süreci rahat- } \\
\text { latıcı etkisi vardır. Doğa ile temas, kısa } \\
\text { vadede, zihinsel ve fiziksel sağllğı korumak, } \\
\text { sosyal ilişkileri sürdürmek için; uzun vadede } \\
\text { ise pandemiye karşı genel kentsel esneklik } \\
\text { oluşturmak için doğrudan önemlidir. }\end{array}$ \\
\hline $\begin{array}{l}\text { "Rural areas at risk } \\
\text { during COVID-19 } \\
\text { pandemic."12 }\end{array}$ & Nisan, 2020 & $\begin{array}{l}\text { Pandemiyle başa çıkmak için, yalnızca kentsel } \\
\text { alanlara odaklanmak yerine sistematik bir } \\
\text { yaklaşım benimsenmelidir. İnsanlar şehirl- } \\
\text { erden kırsal alanlara göç etmektedir. }\end{array}$ \\
\hline $\begin{array}{l}\text { "COVID-19 attack } \\
\text { rate increases with } \\
\text { city size." }{ }^{13}\end{array}$ & Nisan, 2020 & $\begin{array}{l}\text { Büyük şehirlerde sosyoekonomik } \\
\text { bağlantıların yoğunluğu ortaya çıkan salgın } \\
\text { hastalıkların kontrolünü zorlaştırmaktadır. } \\
\text { Ancak diğer yandan COVID-19 bulaşını } \\
\text { durdurmak için gerekli olan bilgilerin yayıl- } \\
\text { masını, sosyal koordinasyonu ve yenilikleri } \\
\text { de kolaylaştırabilir. Bu bilgilerin ve ilişkili } \\
\text { eylemlerin virüsten çok daha hızlı yayılması } \\
\text { sağlanır ise sosyoekonomik bağlantılar } \\
\text { avantaja dönüşebilir. }\end{array}$ \\
\hline $\begin{array}{l}\text { "Coronavirus ques- } \\
\text { tions that will not go } \\
\text { away: interrogating } \\
\text { urban and socio-spa- } \\
\text { tial implications } \\
\text { of COVID-19 } \\
\text { measures"14 }\end{array}$ & Nisan, 2020 & $\begin{array}{l}\text { Pandemi sonrası kentsel hareketliliği veya } \\
\text { hareket modellerini anlamak, ihtiyaçlar } \\
\text { doğrultusunda şehir tasarımlarının değişm- } \\
\text { esi için çok önemli olacaktır. }\end{array}$ \\
\hline $\begin{array}{l}\text { "Pandemic-Resil- } \\
\text { ient Community } \\
\text { Planning." }{ }^{0}\end{array}$ & Nisan, 2020 & $\begin{array}{l}\text { Pandemiler, toplulukların karşılaștı̆ı̆ birçok } \\
\text { riskten sadece biridir ve genellikle en önemlisi } \\
\text { değildir, bu nedenle, diğer riskler göz ardı } \\
\text { edilerek klasik bulaşıcı hastalık kontrol strate- } \\
\text { jilerini uygulamak verimli olmayacaktır. } \\
\text { Birçok "kazan-kazan" çözümü, pandemi } \\
\text { risklerini azaltma, trafik sorunlarını ve kirlilik } \\
\text { emisyonlarını azaltma, fiziksel aktiviteyi } \\
\text { arttırma gibi, diğer topluluk hedeflerine } \\
\text { ulaşmaya yardımcı olabilir. }\end{array}$ \\
\hline
\end{tabular}

Pandemi ile edinilen tecrübelerin şehircilik anlayışı üzerinde önemli bir etkiye yol açacağı, gelecekte daha insan merkezli şehir planlamalarının önü açılacağı vurgulanmaktadır., ${ }^{40115}$ 'Salgın Dirençli Şehir Planlaması' da denilen yaklaşım ile, ileride olası bir bulaşıcı hastalığın, bulaşma risklerini en aza indirecek ve sağlık ve güvenliği en üst düzeye çıkaracak ya- şam alanları tasarlamak hedeflenmektedir. Örneğin kalabalık nüfuslu, ortak girişi olan, kapalı-dar koridorları ve asansörleri bulunan binaların ek riskler sunacağı, sık sık hijyen koşullarının sağlanması gerektiği farkındalığı oluşmuştur. ${ }^{10}$

Bir şehrin kırsal ve kentsel alanlarında karşılaşılabilecek pandemi riskleri farklılık gösterir. Örneğin kentsel alanda kalabalık binalar ve kaldırımlar, asansörler gibi kapalı ve ortak kullanım alanları, toplu taşıma araçları veya yetersiz barınma koşulları ön planda iken; kırsal alanlarda ise hassas (yaşlı, yoksul, kronik hastalık vb.) gruplar, sağlık hizmetine sınırlı erişim, yetersiz konut ve hijyen koşulları, yoksulluk ve sınırlı istihdam ön plandadır. ${ }^{10}$ Her risk yerel yönetimler açısından ortaya konulmalı, yeni planlamalar yapılmalıdır.

Pandemi sürecinde Dünya’nın farklı bölgelerinde bulunan şehirlerin yaşadığı benzer sorunları tartışmak, farklı yaklaşımları görmek, hızlı bilgi alışverişi sağlamak için ortak platformda buluşmak amacıyla "Cities for Global Health" projesi başlatılmıştır. İçinde Türkiye’den İstanbul, İzmir, Antalya gibi illerin de bulunduğu platformda, bugün için 28 ülke 71 şehir katılımı bulunmaktadır. Projenin kendi adıyla bir web sitesi bulunmaktadır. Web sitesi İngilizce, İspanyolca ve Fransızca olarak hizmet vermektedir. ${ }^{16}$

Şehirlerin hazırlık yapabilmesi, mevcut durumlarını kontrol edebilmesi ve daha iyi müdahalelerde bulunabilmesi için "pandemi hazırlık endeksleri” geliştirilmeye çalışılmaktadır. ${ }^{17}$ Georgetown Üniversitesi Küresel Sağlık Bilimi ve Güvenliği Merkezi, yerel yönetimlerin halk sağlığı sorunlarına hazırlıklı olmaları ve müdahale kapasitelerini değerlendirebilmeleri için Mart 2020'de bir değerlendirme aracı kullanıma sunmuştur. RUHSA (Rapid Urban Health Security Assessment)-Hizlı Kentsel Sağlık Güvenliği Değerlendirmesi ismini verdikleri değerlendirme aracına Georgetown Üniversitesi’nin erişim linkinden ücretsiz ulaşılabilmektedir. ${ }^{18}$

RUHSA değerlendirme aracı dört ana başlıktan oluşmaktadır. Bunlar önleme, tespit, yanıt ve diğer hususlar olarak adlandırılmıştır. Her başlık, kendi içinde alt başlıklara ayrılmaktadır. Ayrıntılar Tablo 3’te sunulmuştur. 


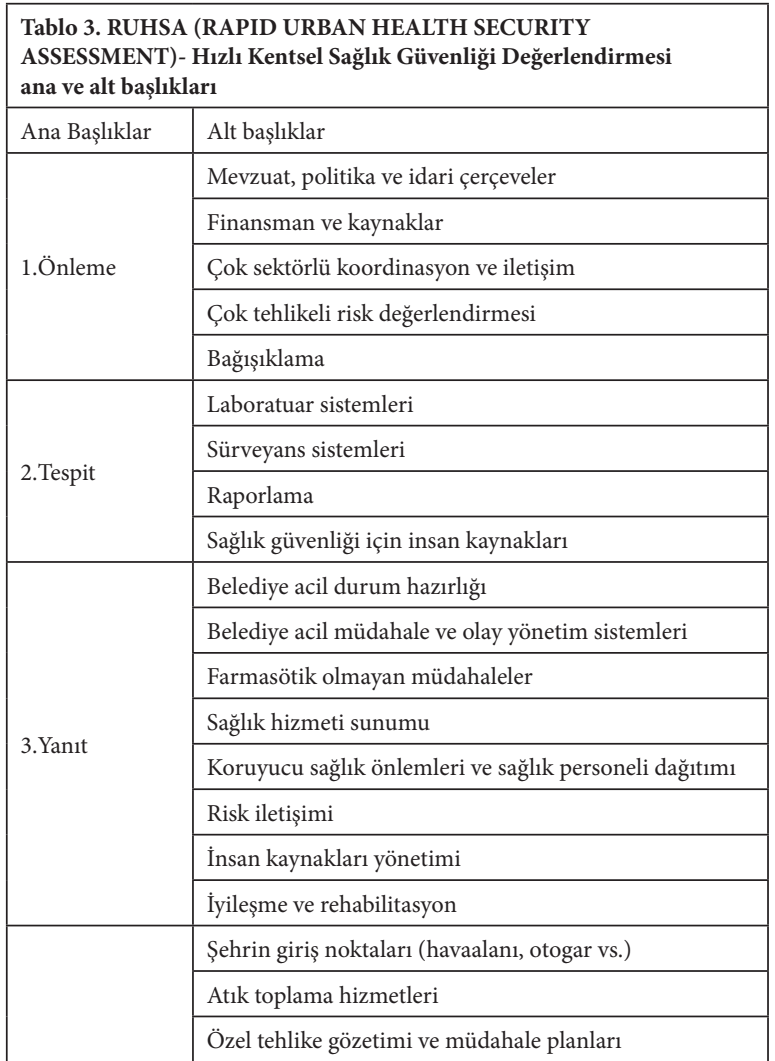

DSÖ, COVID-19 gibi süreçlerde çok hızlı, acil ve yaygın bir şekilde harekete geçebilecek bir ağa sahiptir. Uluslararası Sağlıklı Şehirler Ağı tüm Dünya’da ulusal ağlara sahiptir. 2018 yılında 30. yılını kutlayan Sağlıklı Şehirler hareketi, "Şehir Sağlığı” kavramının yaygınlaştırılması için yerel düzeyde kullanılan temel bir araçtır. 1993 yılında Türkiye'nin de dahil olduğu bu hareket kapsamında 2005 yılında Türkiye Sağlıklı Kentler Birliği kurulmuştur. COVID-19 sürecinde DSÖ online COVID-19 platformu kurmuştur. Uluslararası Sağlıklı Şehirler Ağı'nın COVID-19 sürecindeki rolünün belirlenmesi ve bundan sonra ortaya çıkacak sağlık acillerinde daha aktif bir görev gücü haline dönüştürülmesinde yarar görülmektedir.

Türkiye'de 17 Nisan 2020 tarihinde, dijital platformda, Gazi Üniversitesi Mimarlık Fakültesi Şehir ve Bölge Planlama Bölümü moderatörlüğünde, farklı üniversite ve disiplinlerin katılımı ile 'Türkiye Belediyeler Birliği (TBB) ve Kent Araştırmaları Enstitüsü Kent Sağlığı Rehberi Hazırlık Çalıştay’ı ya- pılmıştır. TBB pandemi sonrası şehirlerin geleceğini tartışmaya açmıştır 19. Tartışma konuları arasında "Geleceğin Ailesi, Sağlıklı Kentler” yer almıştır.

Sonuç olarak, geleceğin en kırılgan ve riskli noktası kentler olduğu unutulmamalıdır. Kentlerde yaşanan her sorunda kaçış yeri kırsal alandır. Kent ve kırın toplamı olan şehirlerin kritik alt yapıları korunmalı ve her düzeyde geliştirme çalışmaları sürdürülmelidir.

Sağlıklı şehir sadece belirli bir sağlık düzeyine ulaşmış şehir değil, sağlık bilincine sahip ve onu geliştirmek için çaba harcayan şehir anlamına gelir. COVID-19 salgını sonucu oluşacak farkındalık ve tecrübeler, daha iyi ve daha sürdürülebilir toplumlar ve şehirler inşa etmek için bir firsata dönüştürülmelidir. Şehir sağlığını belirleyen göstergeler ışı̆̆ında, pandemi verileri analiz edilerek, bütüncül bir bakış açısıyla değerlendirilmeli, eksiklikler saptanmalı ve yeni çalışmalar planlanmalıdır. Süreç, hazırlıklı olma, erken uyarı sistemleri, olayı iyi yönetme, olay geçtikten sonra hızla normal yaşama dönme, her tür iklim ve sağlık acillerine uyumlu ve dirençli hale gelmenin önemini gözler önüne sermiştir. Bir başka gerçek de; bundan sonra yapılması düşünülen ve/veya geliştirilmesi düşünülen her plan, program, proje vb. yerel düzeyde, o bölgenin ve bölgede bulunan özellikli grupların ihtiyaçlarına göre hazırlanmalıdır. Ev, apartman, site, mahalle, şehir risk noktaları belirlenmelidir.

Türkiye 1930 yıllarında hayata geçirdiği Belediyeler Kanunu ve Umumi Hıfzıssıhha Kanunu ile yerleşmiş, köklü bir yerel yönetim ve halk sağlığı hizmeti yapısına sahiptir. Şehir sağlığ kavramı bu iki kanunda da detaylı bir şekilde anlatılmıştır. Pandemi sürecinde yapılan yerel düzenlemeler "Umumi Hıfzıssihha Kurulları" tarafından yönetilmektedir. Var olan bu alt yapıya eklenen pandemi kurulları da şehirde sağlığın geliştirilmesinde önemli bir görev almalıdır. 
J Biotechnol and Strategic Health Res. 2020;1(Özel Sayı):147-151

DENIZ, KİRAZ, COVID-19 ve Şehir Sağlığı

\section{Kaynaklar}

1. COVID-19 (SARS-CoV-2 Enfeksiyonu) Rehberi, T.C. Sağglk Bakanlı̆̆ı Halk Sağlı̆̆ı Genel Müdürlüğü, 14 Nisan 2020, 2020;19.

2. https://www.who.int/dg/speeches/detail/who-director-general-s-opening-remarks-at-themedia-briefing-on-COVID-19---11-march-2020. doi:10.1007/s12603-017-0883-6, Erișim Tarihi: 23.04 .2020

3. https://www.who.int/emergencies/diseases/novel-coronavirus-2019/advice-for-public. Erișim Tarihi: 23.04.2020

4. Hang M: Preparing cities for epidemics: Lessons from the COVID19 outbreak. The Urban Now: International Journal of Urban and Regional Research.

5. Gu, C., Jiang, W., Zhao, T., \& Zheng, B. (2020). Mathematical recommendations to fight against COVID-19. Retrieved from $h t t p: / / d x$. doi.org/10.2139/ssrn.3551006.

6. Tian, H., Liu, Y., Li, Y., Wu, C.-H., Chen, B., Moritz, U. G. K., Dye, C. (2020). An investigation of transmission control measures during the first 50 days of the COVID-19 epidemic in China. Science, 10.1126/sc, 1-13. https://doi.org/10.1126/science.ab.

7. https://www.icisleri.gov.tr/. Erișim Tarihi: 23.04.2020

8. Caria, S., Fetzer, T., Fiorin, S., Goetz, F., Gomez, M., Haushofer, J., Yoeli, E. (2020). Measuring Worldwide COVID-19 Attitudes and Beliefs. Retrieved April 9, 2020, from https:// osf.io/3sn $2 k /)$.

9. Schou C, Heegaard NHH, Electrophoresis. Brooks, S. K., Webster, R. K., Smith, L. E., Woodland, L., Wessely, S., Greenberg, N., \& Rubin, G. J. (2020). The psychological impact of quarantine and how to reduce it rapid review of the evidence. The Lancet, 395(10227), 912-920. httpsdoi.org10.1016S01.

10. Litman, Todd. "Pandemic-Resilient Community Planning." 2020. Erișim Tarihi: 23.04.2020 11. Samuelsson K, Barthel S, Colding J, Macassa G, Giusti M. Urban nature as a source of resilience during social distancing amidst the coronavirus pandemic, 2020.

12. Ranscombe, Peter. "Rural areas at risk during COVID-19 pandemic." The Lancet Infectious Diseases (2020)

13. Stier AJ, Berman MG, Bettencourt LMA. COVID-19 attack rate increases with city size. 2020:1-23. http://arxiv.org/abs/2003.10376.

14. Salama AM. Coronavirus questions that will not go away: interrogating urban and socio-spatial implications of COVID-19 measures [version 1; peer review: 1 approved ], 2020

15. Badger E. Density is normally good for us: That will be true after Coronavirus, too. The Upshot - The New York Times (24 March 2020), 2020

16. https://www.citiesforglobalhealth.org/. Erisim Tarihi: 23.04 .2020

17. https://www.weforum.orgagenda202003how-should-cities-prepare-for-coronavirus-pandemics. Erișim Tarihi: 23.04 .2020

18. https://georgetown.app.box.com/s/0sruh3cnji6txorqt2acgm0z9xx73ac1. Erişim Tarihi: 23.04.2020

19. https://www.tbb.gov.tr/basin-ve-yayin/haberler/20200421-salgin-sonrasi-sehirlerin-gelecegi-tartisildi. Erişim Tarihi: 23.04.2020 